\title{
Poor nutritional status of schoolchildren in urban and peri-urban areas of Ouagadougou (Burkina Faso)
}

\author{
Charles Daboné $^{1,2}$, Hélène F Delisle ${ }^{1 *}$ and Olivier Receveur ${ }^{1}$
}

\begin{abstract}
Background: Malnutrition is still highly prevalent in developing countries. Schoolchildren may also be at high nutritional risk, not only under-five children. However, their nutritional status is poorly documented, particularly in urban areas. The paucity of information hinders the development of relevant nutrition programs for schoolchildren. The aim of this study carried out in Ouagadougou was to assess the nutritional status of schoolchildren attending public and private schools.

Methods: The study was carried out to provide baseline data for the implementation and evaluation of the Nutrition Friendly School Initiative of WHO. Six intervention schools and six matched control schools were selected and a sample of 649 schoolchildren (48\% boys) aged 7-14 years old from 8 public and 4 private schools were studied. Anthropometric and haemoglobin measurements, along with thyroid palpation, were performed. Serum retinol was measured in a random sub-sample of children $(N=173)$. WHO criteria were used to assess nutritional status. Chi square and independent t-test were used for proportions and mean comparisons between groups.

Results: Mean age of the children ( $48 \%$ boys) was $11.5 \pm 1.2$ years. Micronutrient malnutrition was highly prevalent, with $38.7 \%$ low serum retinol and $40.4 \%$ anaemia. The prevalence of stunting was $8.8 \%$ and that of thinness, $13.7 \%$. The prevalence of anaemia $(p=0.001)$ and vitamin A deficiency $(p<0.001)$ was significantly higher in public than private schools. Goitre was not detected. Overweight/obesity was low (2.3\%) and affected significantly more children in private schools $(p=0.009)$ and younger children $(7-9 y)(p<0.05)$. Thinness and stunting were significantly higher in peri-urban compared to urban schools ( $p<0.05$ and $p=0.004$ respectively). Almost 15\% of the children presented at least two nutritional deficiencies.

Conclusion: This study shows that malnutrition and micronutrient deficiencies are also widely prevalent in schoolchildren in cities, and it underlines the need for nutrition interventions to target them.
\end{abstract}

\section{Background}

Despite the economic growth observed in developing countries, malnutrition and particularly undernutrition is still highly prevalent [1]. Concurrently, a growing prevalence of obesity and its related chronic diseases is being observed in these countries [2]. Increasing obesity is already a major concern in developed countries for pre-school children [3] as well as schoolchildren[4]. In developing countries, this rising epidemic along with the

\footnotetext{
* Correspondence: helene.delisle@umontreal.ca

'TRANSNUT- Department of Nutrition, Faculty of Medicine, University of Montreal, 2405 Chemin de la Côte Ste Catherine, Montreal Qc, H3T 1A8, Canada

Full list of author information is available at the end of the article
}

persistence of undernutrition and infections typifies the 'Double Burden of Malnutrition' (DBM) [5], which is becoming of great concern for African countries [6]. Indeed, the DBM is a real threat at the population, household and even individual level [7], and it is now observed among schoolchildren [8]. Rural areas of developing countries are generally prioritized as regards nutrition intervention, because undernutrition is more widespread than in urban areas [9]. However, a shift is occurring and children in the cities are at risk of both over-nutrition and undernutrition [10]. Some studies are now highlighting the problem of micronutrient deficiencies in cities [11] and among schoolchildren in particular [12]. Schoolchildren are dramatically affected by
C Biomed Central

() 2011 Daboné et al; licensee BioMed Central Ltd. This is an Open Access article distributed under the terms of the Creative Commons Attribution License (http://creativecommons.org/licenses/by/2.0), which permits unrestricted use, distribution, and reproduction in any medium, provided the original work is properly cited. 
anaemia [12], vitamin A deficiency [13] and parasitic infections [14] with adverse impact on their nutritional status $[15,16]$, as well as on their cognitive development and school performance [17-19]. Unfortunately, the paucity of nutrition information on this vulnerable population makes it difficult to define appropriate intervention strategies. Demographic and Health Surveys (DHS), which provide nutritional status data at national level, do not include schoolchildren [11,20-23]. Furthermore, the few available data usually pertain to rural schoolchildren so that school nutrition programmes are more likely to be implemented in rural areas than urban [24], as observed in Burkina Faso [25].

Recent surveys at national level in Burkina Faso revealed a high prevalence of malnutrition among rural schoolchildren [26]. The aim of the present study was to assess the nutritional status of schoolchildren attending private and public schools covering both the urban and the peri-urban areas of Ouagadougou (Burkina Faso). We hypothesized that undernutrition and micronutrient malnutrition would be widespread, and that public school pupils, particularly in peri-urban areas, would be most affected.

\section{Methods \\ Setting}

We conducted between October 2008 and March 2009 a cross-sectional study in 12 public and private schools in Ouagadougou, the capital city of Burkina Faso (West Africa). Ouagadougou is located in the Kadiogo province, Central region. The city and its peri-urban areas were covered in this study which was to serve as baseline for the subsequent implementation and evaluation of the Nutrition Friendly School Initiative of WHO and its partners [27].

\section{Population and sample}

Anaemia was used to estimate sample size, as it is the number one nutritional problem at school age [28]. Based on an estimated prevalence of $40 \%$ in this population [26], 350 children were required in each group (intervention and control) in order to allow for detecting a $10 \%$ decline in this prevalence after three years of intervention, with $5 \%$ alpha error and $80 \%$ power. A total number of 770 subjects were selected to allow for refusals and for incomplete data. Only $5^{\text {th }}$ grade classes were included as pupils had to fill-out a self-administered questionnaire. According to the Ministry of primary education, $60 \%$ of pupils at this grade can write and read fluently [29]. For practical reasons, all children of the class were invited to take part in the study. As the mean number of pupils per class is around 60 [29], a total of 12 schools was required. The purposive sample of six "intervention" schools in Ouagadougou was selected with the Ministry of primary education according to specific criteria: committed school staff; public and private schools; urban and peri-urban schools; confessional and non-confessional schools; and schools with a complete primary level of six grades, with at least $40 \%$ of girls. The intervention schools included 4 public schools (one in a peri-urban area) and 2 private schools (one confessional), all located in different city neighbourhoods. These six schools were then matched with 6 control schools on the basis of size, location (urban/ peri-urban), and type (private/public; confessional/non confessional).

\section{Anthropometric measurements}

To assess the nutritional status of pupils, we measured weights and heights according to standard procedures described by WHO [30]. Weight was measured to the nearest $0.1 \mathrm{~kg}$ with an electronic scale (SECA 803) with children wearing only light clothing and without shoes. Weight was recorded twice and the mean value was used in the analyses. If the difference between the two measures exceeded $0.2 \mathrm{~kg}$, the child was weighed again. The scale was checked for accuracy with standard weights after about every 200 measures. Individual height was measured with a wooden stadiometer placed on a flat surface. The subject stood on the basal part of the device with feet together (without shoes). The shoulders, the buttocks and the heels had to touch the vertical measuring board. The children standing with their eyes in the Frankfort horizontal plane, the height was measured to the nearest $0.1 \mathrm{~cm}$ and recorded twice. Similarly, when the difference between the two measures was higher than $0.5 \mathrm{~cm}$, a third measure was taken and the mean of the two closest values was used in the analyses. Computed Z-scores of Body Mass Index for age (BMIAZ) and height for age (HAZ) were then used to assess thinness/overweight/obesity and stunting, respectively, using the WHO new reference values for school boys and girls [31]. Stunting was defined as $H A Z<-2.0$, thinness as BMIAZ $<-2.0$, overweight as BMIAZ $>1.0$ and obesity as BMIAZ $>2.0$ [32].

\section{Biological variables}

Haemoglobin $(\mathrm{Hb})$ concentration to assess anaemia was measured in all children with the HemoCue ${ }^{\circledR}$ system (HemoCue, Angelholm, Sweden). The technique is recommended by WHO for field surveys because of its comparability with the cyanmethemoglobin method [33]. One drop of capillary blood is carefully collected at the tip of the middle finger with a lancet. The first two drops are discarded and the third one is used to fill the microcuvette, which is then placed in the cuvette holder of the device (HemoCue $\mathrm{Hb} 201^{+}$). The displayed $\mathrm{Hb}$ value is then recorded [34]. When the displayed value 
was lower or equal to $7 \mathrm{~g} / \mathrm{dl}$, a second measure was performed and the mean value was recorded for analyses. Age-specfic criteria were used to identify anaemic children: $\mathrm{Hb}<11.5 \mathrm{~g} / \mathrm{dl}$ for children between 7 and 11 years of age, and $\mathrm{Hb}<12 \mathrm{~g} / \mathrm{dl}$ for those aged $12-14$ years [33].

Vitamin A status was assessed in a random subsample of 208 children (half boys) because of the high cost of the assay. We collected $10 \mathrm{ml}$ of venous blood. After centrifugation at the National Public Health Laboratory (NPHL) of Burkina Faso, the serum samples were analysed in duplicate for retinol with High Performance Liquid Chromatography (HPLC) at the Analytical chemistry laboratory of University of Ouagadougou. The laboratory belongs to a network for quality control of retinol determinations. Low serum retinol indicating vitamin A deficiency (VAD) was defined as $<0.7 \mu \mathrm{mol} / \mathrm{l}$ [35].

Thyroid palpation was performed on all children as a means of assessing iodine deficiency, as described and recommended by WHO to detect goitre in school children [36]. The palpation was performed by a trained medical student in his last year at the Medical School of University of Ouagadougou. The simplified method of grading goitre in three categories was used [36].

\section{Statistical analyses}

Data were processed and analysed with SPSS.17 software (SPSS, Inc., Chicago IL). To ensure data quality, data of $30 \%$ of the records were entered twice. Chi square and independent $\mathrm{t}$-test were used for proportions and mean comparisons between groups. All the statistical tests in this study were considered significant at $P<0.05$.

\section{Ethical considerations}

The study was approved by the research ethics committee of the Faculty of Medicine of University of Montreal and the ethics committee of the Ministry of Health of Burkina Faso. The study's objectives and procedures were explained during meetings held in each school. Informed consent forms were given to the children for their parents to sign and were collected one week later. Children whose parents did not accept undertook other activities with the teachers during data collection. The children themselves also had to agree (orally) to take part in the study, and none refused.

\section{Results}

\section{Socio-demographic characteristics}

Eight public and 4 private schools were included in the study. Their location is shown in Figure 1. As shown in the figure, the selected schools were from various areas throughout the entire city, and two of the eight public schools were located in peri-urban areas. A total of 935

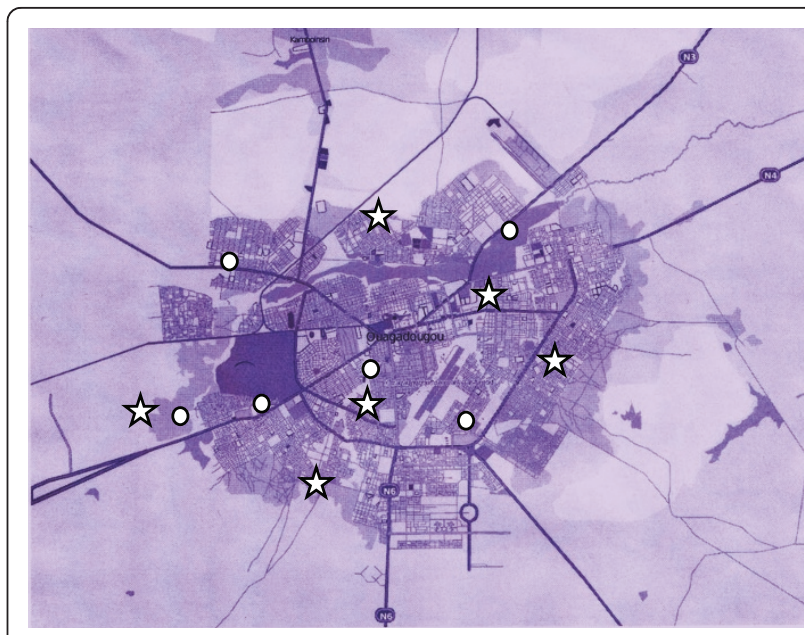

Figure 1 Map of Ouagadougou locating the 12 schools included in the study. Star - Intervention schools; Circle - Control schools

children were invited to participate in the study and 806 parents $(86.2 \%)$ gave their consent. Since seven subjects were missing at the time of data collection, 799 children were finally included (85.5\% response rate). The age ranged from 7 to18 years. We only retained data for the subjects aged between 7 and 14 years (784 subjects) because of the impact of puberty on body measurements. We chose 14 years as cut-off as puberty is likely delayed as frequently observed in developing countries $[37,38]$. In a longitudinal study in Senegal, mean age at menarche among adolescents (12-17 years old) was 17.2 $\mathrm{y}, 16.5 \mathrm{y}$ and $15.6 \mathrm{y}$ for those who were significantly, mildly, or non-stunted during preschool years, respectively [39]. We also excluded from the analyses pupils whose date of birth was not known (135 subjects). Hence 649 subjects in the total sample and 173 subjects in the sub-sample with complete data were retained for the analyses.

As shown in table 1 the sample included more girls (52.4\%) than boys (47.6\%). Mean age was $11.5 \pm 1.2$ years, with 11 years as the mode (34.5\%). A total of 457 pupils (70.4\%) were in public schools while 192 (29.6\%) were in private schools. Peri-urban school children represented $16.3 \%$ of the total. The sex ratio was the same in the subsample and in the whole sample. Similarly the proportion of pupils attending public/private $(70 / 30 \%)$ and urban/peri-urban (84/16\%) schools was roughly the same in the global and the subsample.

\section{Prevalence of malnutrition}

Figure 2 depicts micronutrient and overall malnutrition rates in the total sample and in the subsample of schoolchildren. Micronutrient malnutrition, namely anaemia and vitamin A deficiency, were highly prevalent, 40.4\% 
Table 1 Sociodemographic characteristics of study children

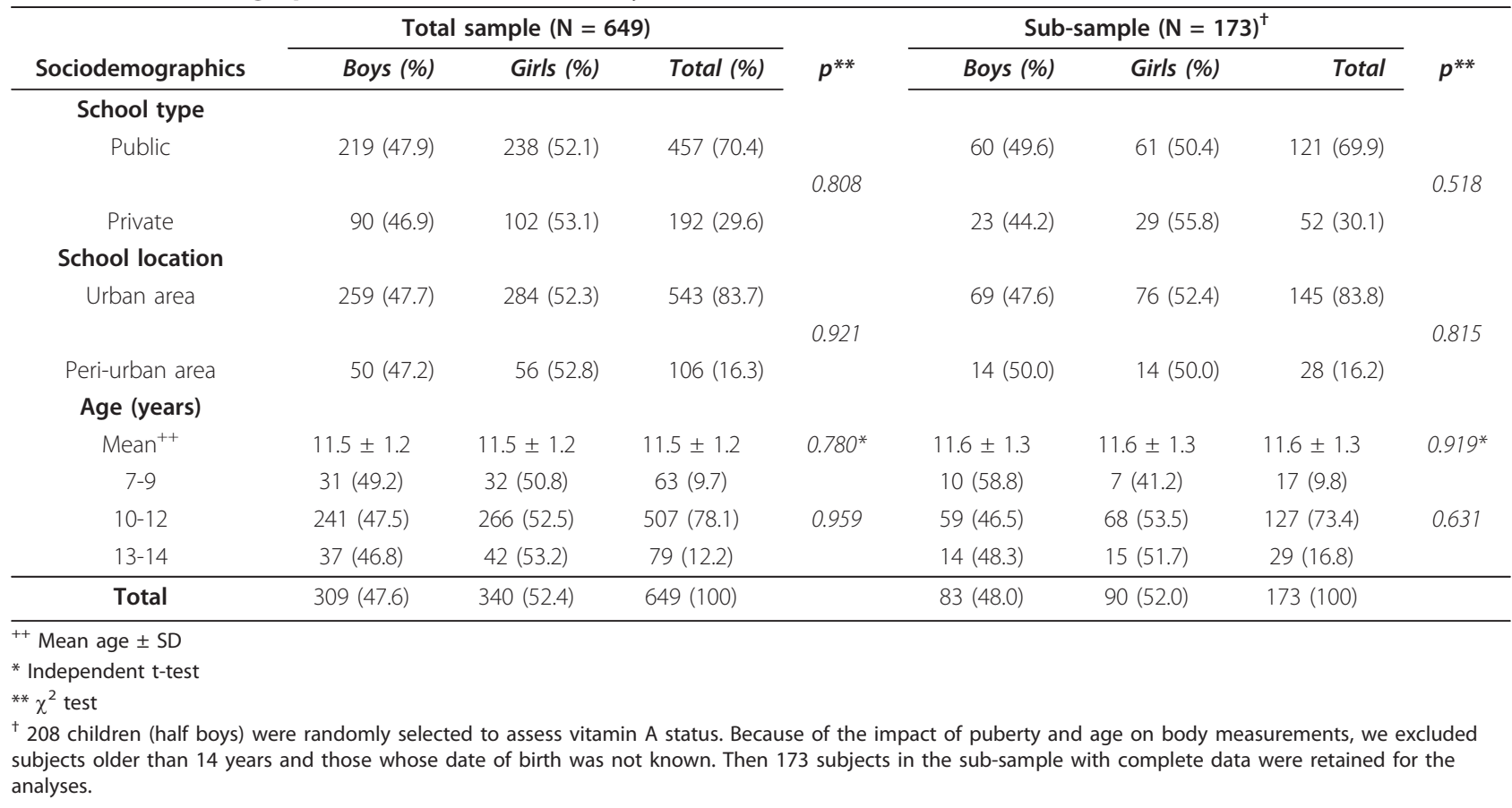

and $38.7 \%$, respectively. Stratifying by sex showed that anaemia affected a same proportion of girls and boys in the sample. While $32.2 \%$ of girls and $45.8 \%$ of boys had vitamin A deficiency, the difference was not significant. No case of goitre was detected with the palpation method.

Regarding overall malnutrition, the stunting rate was $8.8 \%, 8.2 \%$ of girls and $9.4 \%$ of boys (non-significant $\mathrm{p}=$

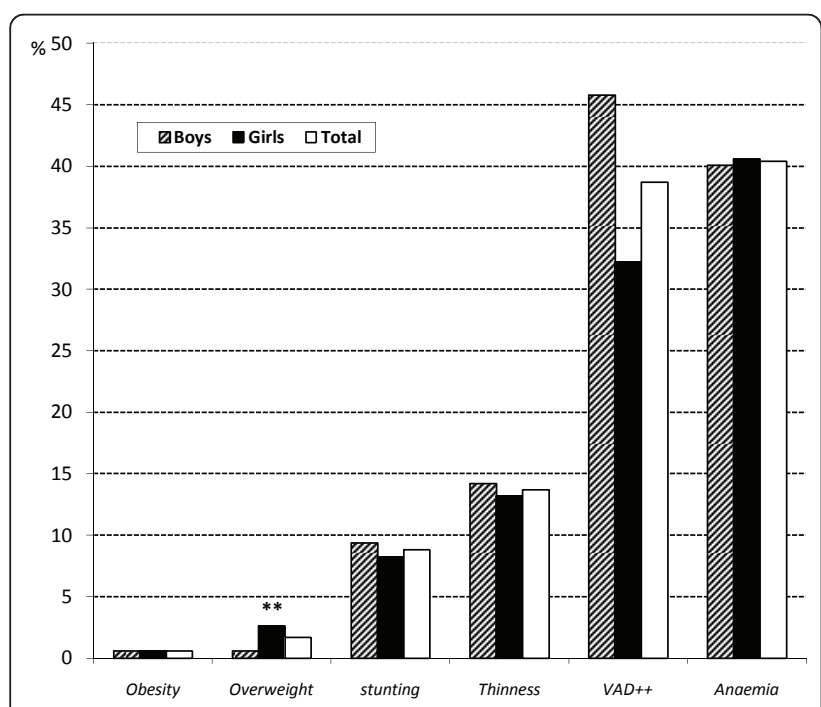

Figure 2 Prevalence of overall and specific malnutrition indicators in schoolchildren in Ouagadougou, Burkina Faso (N = 649). ${ }^{* *} p=0.049$ between boys and girls $\left(\chi^{2} \text { test }\right)^{++} N=173$
0.605). Thinness affected $13.7 \%$ of schoolchildren and there was no significant difference between boys (14.2\%) and girls (13.2\%). There were only four cases of obesity (two boys and two girls), but it was noted that overweight was slightly higher $(1.7 \%)$ with a significant difference $(\mathrm{p}<0.05)$ between boys $(0.6 \%)$ and girls $(2.6 \%)$. Only one child out of the 77 under 10 years of age was underweight (results not shown).

Table 2 gives the number of malnutrition signs in the subjects. While $43 \%$ were within acceptable measures of nutritional well-being, $57 \%$ of the children had at least one sign of malnutrition, including $14.6 \%$ who presented with two or three indicators of malnutrition. Table 2 also provides details on concurrent deficiencies affecting children according to sex. The combination of anaemia and VAD (20.2\%) was the most widespread followed by thinness and anaemia (6\%). Only stunting combined with thinness showed a significant difference $(\mathrm{p}<0.05)$ between boys and girls ( $1.9 \%$ and $0.3 \%$ respectively).

Table 3 displays malnutrition rate by age. The 13-14 year-old group was the most affected by thinness (20.3\%) and anaemia (45.6\%), followed by those of 7-9 y (14.3\%) and $10-12$ y (12.6\%) for thinness and those of $10-12$ y $(40.8 \%)$ and $7-9$ y (30.2\%) for anaemia. The children aged 10-12 years old were the most affected with VAD (43.3\%). However, the age differences in proportions of micronutrient malnutrition were not statistically significant.

The differences in the prevalence of stunting across age groups were statistically significant $(p<0.001)$, and 
Table 2 Malnutrition signs in schoolchildren in Ouagadougou

\begin{tabular}{|c|c|c|c|c|}
\hline \multirow[b]{2}{*}{ Number of signs $(\mathrm{N}=649)$} & \multicolumn{3}{|c|}{ Percentage (Frequency) } & \multirow[b]{2}{*}{$\begin{array}{l}P \\
\text { value* }\end{array}$} \\
\hline & Boys & Girls & Total & \\
\hline Zero (0) & $\begin{array}{l}42.1 \\
(130)\end{array}$ & $\begin{array}{l}43.8 \\
(149)\end{array}$ & $\begin{array}{l}43.0 \\
(279)\end{array}$ & \\
\hline One (1) or more & $\begin{array}{l}57.9 \\
(179)\end{array}$ & $\begin{array}{l}56.2 \\
(191)\end{array}$ & $\begin{array}{l}57.0 \\
(370)\end{array}$ & 0.652 \\
\hline Two (2) & $\begin{array}{l}14.2 \\
(44)\end{array}$ & $\begin{array}{l}12.1 \\
(41)\end{array}$ & $\begin{array}{l}13.1 \\
(85)\end{array}$ & 0.411 \\
\hline Stunting + Thinness & $1.9(6)$ & $0.3(1)$ & $1.1(7)$ & 0.042 \\
\hline Stunting + Anaemia & $3.2(10)$ & $3.5(12)$ & $3.4(22)$ & 0.837 \\
\hline Thinness + Anaemia & $6.5(20)$ & $5.3(18)$ & $5.9(38)$ & 0.523 \\
\hline Stunting $+V A D^{t+}$ & $3.6(3)$ & $5.6(5)$ & $4.6(8)$ & 0.544 \\
\hline Thinness + VAD ${ }^{+t}$ & $3.6(3)$ & $2.2(2)$ & $2.9(5)$ & 0.585 \\
\hline Anaemia $+V A D^{+t}$ & $24.1(20)$ & $16.7(15)$ & $20.2(35)$ & 0.224 \\
\hline Three (3) & $1.9(6)$ & $1.2(4)$ & $1.5(10)$ & 0.429 \\
\hline $\begin{array}{l}\text { Stunting + Thinness }+ \\
\text { Anaemia }\end{array}$ & $1.0(3)$ & $0.0(0)$ & $0,5(3)$ & 0.069 \\
\hline $\begin{array}{l}\text { Stunting + VAD + } \\
\text { Anaemia }^{++}\end{array}$ & $1.2(1)$ & $4.4(4)$ & $2.9(5)$ & 0.204 \\
\hline $\begin{array}{l}\text { Thinness + Anaemia + } \\
V A D^{++}\end{array}$ & $2.4(2)$ & $0.0(0)$ & $1.2(2)$ & 0.139 \\
\hline
\end{tabular}

${ }^{++}$For multi-deficiencies including VAD, $\mathrm{N}=173$

* $\chi^{2}$ test

so were the differences of overweight/obesity $(\mathrm{p}<0.05)$. Youngest children (7-9 y) did not present with stunting while the older children (13-14 y) were the most affected group with $19.0 \%$ prevalence, followed by $10-12$ y group (8.3\%). Conversely, while older children did not present with overweight/obesity their younger peers (7-9 y) were more affected (6.3\%) followed by the 10-12 y group with $2.2 \%$ prevalence.

When comparing the nutritional status of the children according to school type (table 4), it appears that pupils attending public schools were significantly more affected by micronutrient malnutrition than those of private schools $(\mathrm{p}=0.001$ and $\mathrm{p}<0.001$ for anaemia and VAD, respectively). Stunting was more frequent in public schools (9.6\%) compared to private schools (6.8\%), although the difference was not significant. Interestingly, overweight/obesity was significantly $(p=0.009)$ more prevalent in private schools (4.7\%) compared to public schools $(1.3 \%)$ whereas the prevalence of thinness was almost the same in the two school types (13\% and $14 \%$ respectively for private and public schools).

As depicted in table 4 stunting (16.0\%) and thinness (19.8\%) were significantly higher in peri-urban than urban schools $(\mathrm{p}=0.004$ and $\mathrm{p}<0.05$ respectively). VAD tended to be more widespread and overweight/ obesity lower in the peri-urban schools than in the urban schools.

\section{Discussion}

The present study showed that malnutrition, whether undernutrition or micronutrient deficiencies, was highly prevalent at school age in urban areas. Almost $60 \%$ of the children examined had at least one sign of malnutrition and roughly $15 \%$ had at least two such indicators. Of particular concern, more than $40 \%$ of the subjects were anaemic and roughly the same percentage were vitamin A deficient. We verified that there was no significant difference in the prevalence of micronutrient malnutrition in the retained subjects compared to the 135 children excluded because their birth date was unknown ( $\mathrm{p}=0.133$ and $\mathrm{p}=0.183$ for VAD and anaemia, respectively: data not shown). These high rates in children (mean age $11.5 \pm 1.2$ years) are similar to those of the national study of schoolchildren in Burkina Faso, whose mean age was $9.7 \pm 5.8$ years [26]. In this study where rural schoolchildren were predominant, $40.5 \%$ were vitamin A deficient and $43.7 \%$ were anaemic. Similarly, in the baseline study of the red palm oil project in selected primary schools of two zones of Burkina Faso (out of the Central region, where Ouagadougou is located), more than $40 \%$ of the children were vitamin A deficient [40]. A high prevalence of micronutrient malnutrition at school age is not uncommon in developing countries [12]. In northern Ethiopia, the prevalence of VAD was $51.1 \%$ in a study conducted in 1997 in 824 pupils aged 6-9 years [41]. In a report on six African

Table 3 Nutritional status of schoolchildren in Ouagadougou according to age

\begin{tabular}{ccccccc}
\hline & & \multicolumn{4}{c}{ Nutritional status (\%) } \\
\cline { 3 - 7 } Age (years) & $\mathbf{N}$ & Overweight/Obesity & Thinness & Stunting & Anaemia & Vitamin A deficiency $^{\text {t+ }}$ \\
\hline $7-9$ & 63 & $4(6.3)$ & $9(14.3)$ & $0(0.0)$ & $19(30.2)$ & $3(17.6)$ \\
$10-12$ & 507 & $11(2.2)$ & $64(12.6)$ & $42(8.3)$ & $207(40.8)$ & $55(43.3)$ \\
$13-14$ & 79 & $0(0.0)$ & $16(20.3)$ & $15(19.0)$ & $36(45.6)$ & $9(31.0)$ \\
$P$ value* & & 0.039 & 0.184 & $<0.001$ & 0.160 & 0.081 \\
\hline Total & 649 & $15(2.3)$ & $89(13.7)$ & $57(8.8)$ & $262(40.4)$ & $67(38.7)$ \\
\hline
\end{tabular}

${ }^{{ }^{+}}$On sub-sample only $(\mathrm{N}=173)$

$* \chi^{2}$ test 
Table 4 Malnutrition of schoolchildren in Ouagadougou according to school characteristics

\begin{tabular}{|c|c|c|c|c|c|c|}
\hline \multirow[b]{2}{*}{ School characteristics } & \multirow[b]{2}{*}{$\mathbf{N}$} & \multicolumn{5}{|c|}{ Nutritional status (\%) } \\
\hline & & Overweight/obesity & Thinness & Stunting & Anaemia & Vitamin A deficiency ${ }^{\dagger+}$ \\
\hline \multicolumn{7}{|l|}{ School type } \\
\hline Public schools & 457 & $6(1.3)$ & $64(14.0)$ & $44(9.6)$ & $204(44.6)$ & $64(52.9)$ \\
\hline Private schools & 192 & $9(4.7)$ & $25(13.0)$ & $13(6.8)$ & $58(30.2)$ & $3(5.8)$ \\
\hline$P$ value ${ }^{*}$ & & 0.009 & 0.740 & 0.241 & 0.001 & $<0.001$ \\
\hline \multicolumn{7}{|l|}{ School location } \\
\hline Urban schools & 543 & $15(2.8)$ & $68(12.5)$ & $40(7.4)$ & $221(40.7)$ & $52(35.9)$ \\
\hline Peri-urban schools & 106 & $0(0.0)$ & $21(19.8)$ & $17(16.0)$ & $41(38.7)$ & $15(53.6)$ \\
\hline$P$ value & & 0.083 & 0.046 & 0.004 & 0.698 & 0.078 \\
\hline Total & 649 & $15(2.3)$ & $89(13.7)$ & $57(8.8)$ & $262(40.4)$ & $67(38.7)$ \\
\hline
\end{tabular}

+† On sub-sample only $(\mathrm{N}=173)$

${ }^{*} \chi^{2}$ test

and two Asian countries, 40.2\% of children aged 7-11 years and $54.4 \%$ of those aged $12-14$ years were anaemic [12]. A similar increasing trend of anaemia with age is observed in the current study (table 3).

We also found that $13.7 \%$ of the children were thin, which is higher than the $8 \%$ prevalence previously reported for Burkina Faso schoolchildren outside the capital city of Ouagadougou [26]. Thinness, or wasting, usually describes acute malnutrition. Our study was conducted between late 2008 and early 2009, that is, during the global economic and food crisis that hit developing countries so hard [42] and which was responsible for reduced access to food particularly among vulnerable populations [43]. We observed that several schoolchildren stayed at school during lunchtime, but did not have pocket money to buy any street food, or did not have enough to eat an adequate meal. This may have played a role in the observed prevalence of thinness in schoolchildren of Ouagadougou. Notwithstanding, this level is far lower than that reported by the Partnership for Child Development (PCD) in schoolchildren of developing countries ten years ago [44].

The prevalence of stunting in our study was lower than in the recent national study of schoolchildren in Burkina Faso (8.8\% vs 12\%) [26], as well as in a nationwide survey in Chad (18.7\%) in a sample of schoolchildren aged between 6 and 15 years [45]. Stunting is an indicator of chronic malnutrition, and at school age, it may reflect malnutrition during the first years of life [1]. Growth deficit tends to accumulate with age and particularly in boys, as observed in our study and in other studies of school-children in developing countries [44]. The higher rate of stunting among older children, depicting an increasing vulnerability with age may also reflect some improvement of food and health conditions over recent years since most of the growth deficit or catch-up takes place before the age of 24 months [46]. Except for overweight/obesity and anaemia, a higher proportion of boys than girls showed signs of malnutrition, as previously reported for stunting and wasting [44], and for VAD [41]. A metanalysis of data from 16 demographic and health surveys conducted in 10 subSaharan countries [23] revealed that boys were more stunted than girls, and speculated on the role of cultural factors or natural selection [23].

Although malnutrition still appears as a priority problem, overweight/obesity should not be overlooked right at school age, as we detected a higher prevalence trend in the youngest group of children. At variance with our study, a much lower prevalence of obesity was reported in $2001(0.26 \%$ vs $0.60 \%)$ in an adolescent population of Ouagadougou (mean age 13.8 y) [47]. However, both studies are consistent in the significantly higher prevalence of overweight observed in girls compared with boys (Figure 2).

It was clearly apparent in our study that private school-children enjoyed a better nutritional status than those attending public schools, with anaemia and VAD significantly higher in the latter (30\% vs $45 \%$ and $6 \%$ vs $53 \%$ respectively). However, it is of note that overweight/obesity was also significantly higher in private than public schools, which is in accordance with previous reports in other developing country schoolchildren [48]. Socio-economic disparities likely underlie these differences [48]. We did not examine the socio-economic conditions of the individual children, but mere differences in school registration fees are convincing: US \$ 60 in private schools compared with only US $\$ 4$ in public schools. Nevertheless, it is surprising that thinness was as common in private as in public schools in our study (13.0\% and $14.0 \%$, respectively). There is no obvious explanation for this high rate of thinness even in private school children.

As could be expected, stunting and thinness were significantly higher in peri-urban than urban schools, and VAD also tended to be higher in the former than latter 
schools (table 4). Poverty and low maternal education are among the determinants of child malnutrition [49]. It is also known that the prevalence of malnutrition is higher in rural than urban areas, particularly stunting [9], which reflects poor socio-economic status as the community level. It is therefore not surprising to find a higher percentage of malnourished children in periurban areas, where people are poorer, and where schools also draw their pupils from the surrounding villages. Anaemia was observed in roughly the same proportion of urban and peri-urban schoolchildren (around $40 \%)$. This confirms that anaemia is the most widespread malnutrition problem in schoolchildren in developing countries [28].

While iron deficiency is the main factor of anaemia [50], it is not the only one, and infection plays a major role [15,51], notably malaria and hookworms in African school-children [14]. In Ouagadougou, for instance, the prevalence of malaria (41.4\%) tended to be the highest in children aged 5-14 years, who were also at the highest risk of infection compared to infants and adults [52]. Other micronutrient deficiencies may also be involved in the aetiology of anaemia [53]. The "top three" micronutrient deficiencies are iron deficiency, VAD and Iodine Deficiency Disorders (IDD) [28]. The high prevalence of anaemia could be a great threat for school-children, particularly since it was combined with VAD in one out of five children (20.2\%) in our study. Indeed iron deficiency and VAD are interrelated [54-56]. In contrast, we detected no goitre using the palpation method recommended by WHO [36], which likely reflects the effectiveness of the salt iodization strategy of the past several decades [57].

To our knowledge, this nutrition study is the first of its kind among city schoolchildren of West Africa. Although the schools were not randomly selected, they represent a broad array of features: public and private, confessional and non-confessional, as well as urban and peri-urban schools. Furthermore, sample size was large enough and in a narrow age-range. However, because of these study features, the results cannot be extrapolated.

School nutrition and feeding programs are usually directed at rural areas [25]. Furthermore, under-five children are the priority target group for strategies and actions to fight malnutrition. There is an urgent need to address nutrition problems among schoolchildren in developing countries, without neglecting urban areas, considering that malnutrition can impair their performance while in school and their productivity later on in life [58].

\section{Conclusion}

Based on our findings, it appears that undernutrition and micronutrient deficiencies are prominent even in urban schoolchildren. Overweight/obesity is still uncommon but it is appearing in private schools and amongst younger children. It may be concluded that the nutrition transition characterized by shifts in dietary habits and lifestyles with resulting increases in the prevalence of obesity and co-morbidity is still in its early stages in the area of the study. The high prevalence of VAD and anaemia and their frequent combination [59] should be of concern and underlines the compelling need for corrective and preventive measures in urban schools, which should no longer be neglected in favour of rural areas.

\section{Acknowledgements}

The authors express their thanks to the Canadian International Development Agency (CIDA) which provided funding for this study through the "Programme Canadien des Bourses de la Francophonie" and "Projet Double Fardeau Nutritionnel". They also thank the "Laboratoire National de Santé Publique" and Helen Keller International of Burkina Faso. Sincere thanks are addressed to schools visited, particularly, school principals and staff, children and their parents.

\section{Author details}

${ }^{1}$ TRANSNUT- Department of Nutrition, Faculty of Medicine, University of Montreal, 2405 Chemin de la Côte Ste Catherine, Montreal QC, H3T 1A8, Canada. 'Laboratoire National de Santé Publique, 09 BP 24 Ouagadougou 09, Burkina Faso.

\section{Authors' contributions}

$C D, H D$ and $O R$ designed the study. CD collected and analysed the field data under the supervision of HD and the co-supervision of OR. CD drafted the paper, $\mathrm{HD}$ and $\mathrm{OR}$ reviewed the draft and made some changes. All authors read and approved the final manuscript.

\section{Competing interests}

The authors declare that they have no competing interests.

Received: 14 December 2010 Accepted: 19 April 2011

Published: 19 April 2011

\section{References}

1. Muller $\mathrm{O}$, Krawinkel M: Malnutrition and health in developing countries. Cmaj 2005, 173(3):279-286.

2. Prentice AM: The emerging epidemic of obesity in developing countries. Int J Epidemiol 2006, 35(1):93-99.

3. Cattaneo A, Monasta L, Stamatakis E, Lioret S, Castetbon K, Frenken F, Manios Y, Moschonis G, Savva S, Zaborskis A, Rito Al, Nanu M, Vignerova J, Caroli M, Ludvigsson J, Koch FS, Serra-Majem L, Szponar L, van Lenthe F, Brug J: Overweight and obesity in infants and pre-school children in the European Union: a review of existing data. Obes Rev 2010, 11(5):389-398.

4. Bertoncello C, Cazzaro R, Ferraresso A, Mazzer R, Moretti G: Prevalence of overweight and obesity among school-aged children in urban, rural and mountain areas of the Veneto Region, Italy. Public Health Nutr 2008, 11(9):887-890

5. FAO: The double burden of malnutrition: Case studies from six developing countries. FAO Food and nutrition paper No84, Rome 2006.

6. Thiam I, Samba K, Lwanga D: Diet related chronic disease in the West Africa Region. in Diet-related chronic diseases and the double burden of malnutrition in West Africa. SCN News 2006, 33:6-10.

7. Delisle HF: Poverty: the double burden of malnutrition in mothers and the intergenerational impact. Ann N Y Acad Sci 2008, 1136:172-184.

8. Fernald LC, Neufeld LM: Overweight with concurrent stunting in very young children from rural Mexico: prevalence and associated factors. Eur J Clin Nutr 2007, 61(5):623-632.

9. Oninla SO, Owa JA, Onayade AA, Taiwo O: Comparative study of nutritional status of urban and rural Nigerian school children. J Trop Pediatr 2007, 53(1):39-43. 
10. McMichael AJ: The urban environment and health in a world of increasing globalization: issues for developing countries. Bull World Health Organ 2000, 78(9):1117-1126.

11. Fotso JC: Urban-rural differentials in child malnutrition: trends and socioeconomic correlates in sub-Saharan Africa. Health Place 2007 13(1):205-223

12. Hall A, Bobrow $E$, Brooker $S$, Jukes $M$, Nokes $K$, Lambo J, Guyatt $H$, Bundy D, Adjei S, Wen ST, Subagio H, Rafiluddin MZ, Miguel T, Moulin S, de Graft Johnson J, Mukaka M, Roschnik N, Sacko M, Zacher A, Mahumane B, Kihamia C, Mwanri L, Tatala S, Lwambo N, Siza J, Khanh LN, Khoi HH, Toan ND: Anaemia in schoolchildren in eight countries in Africa and Asia. Public Health Nutr 2001, 4(3):749-756.

13. Singh V, West KP Jr: Vitamin A deficiency and xerophthalmia among schoolaged children in Southeastern Asia. Eur J Clin Nutr 2004, 58(10):1342-1349.

14. Brooker S, Clements AC, Hotez PJ, Hay SI, Tatem AJ, Bundy DA, Snow RW: The co-distribution of Plasmodium falciparum and hookworm among African schoolchildren. Malar J 2006, 5:99.

15. Awasthi $S$, Bundy D: Intestinal nematode infection and anaemia in developing countries. Bmj 2007, 334(7603):1065-1066.

16. Casapia M, Joseph SA, Nunez C, Rahme E, Gyorkos TW: Parasite risk factors for stunting in grade 5 students in a community of extreme poverty in Peru. Int J Parasitol 2006, 36(7):741-747.

17. Pollitt E: Early iron deficiency anemia and later mental retardation. Am Clin Nutr 1999, 69(1):4-5.

18. Singh M: Role of micronutrients for physical growth and mental development. Indian J Pediatr 2004, 71(1):59-62.

19. Florence MD, Asbridge $M$, Veugelers PJ: Diet quality and academic performance. J Sch Health 2008, 78(4):209-215, quiz 239-241.

20. INSD: Enquête Démographique et de Santé (EDS) 1993. Institut National de la statistique et de la démographie, Ouagadougou-Burkina-Faso 1994

21. INSD: Enquête Démographique et de Santé (EDS) 1998. Institut National de la statistique et de la démographie, Ouagadougou-Burkina-Faso 1999.

22. INSD: Enquête Démographique et de Santé (EDS) 2003. Institut National de la statistique et de la démographie, Ouagadougou-Burkina-Faso 2004.

23. Wamani H, Astrom AN, Peterson S, Tumwine JK, Tylleskar T: Boys are more stunted than girls in sub-Saharan Africa: a meta-analysis of 16 demographic and health surveys. BMC Pediatr 2007, 7:17.

24. Bundy D, Burbano C, Grosh M, Gelli A, Jukes M, Drake L: Rethinking School Feeding: Social Safety Nets, Child Development, and the Education Sector. The World Bank 2009.

25. Kazianga $\mathrm{H}$, Walque D, Alderman H: Educational and Health Impact of Two School Feeding Schemes: Evidence from a Randomized Trial in Rural Burkina Faso. Policy Research Working Paper Series, The World Bank 2009, 4976.

26. MEBA: Enquête de base du projet de santé et nutrition scoliare- Rapport présenté par Helen Keller International (HKI). Ministère de l'Enseignement de Base et de l'Alphabétisation-Burkina Faso 2007, 31.

27. WHO: Nutrition-Friendly Schools Initiative (NFSI).[http://www.who.int/ nutrition/topics/nutrition_friendly_schools_initiative/en/].

28. Ramakrishnan U: Prevalence of micronutrient malnutrition worldwide. Nutr Rev 2002, 60(5 Pt 2):S46-52.

29. DEP/MEBA: Synthèse des données statistiques de l'éducation de base 2006-2007. BURKINA FASO-Ministère de l'Enseignement de Base et de I'Alphabétisation/Direction des Etudes et de la planification 2007.

30. OMS: Utilisation et interpretation de l'anthropométrie. Rapport d'un comité OMS d'experts. Serie de rapports techniques 8541995.

31. De Onis M, Onyango AW, Borghi E, Siyam A, Nishida C, Siekmann J: Development of a WHO growth reference for school-aged children and adolescents. Bull World Health Organ 2007, 85(9):660-667.

32. WHO: WHO Reference 2007. SPSS macro package. 2008.

33. WHO: Iron Deficiency Anemia; Assessment, Prevention, and Control. A guide for programme managers. WHO/NHD/013 2001.

34. HemoCue AB: La mesure précise de du taux d'hémoglobine, n'importe quand, n'importe où.[http://www.hemocue.com/].

35. WHO: Indicators for assessing Vitamin A Deficiency and their application in monitoring and evaluating intervention programmes. WHO/NUT/9610 1996.

36. WHO: Assessment of lodine Deficiency Disorders and Monitoring their Elimination. A guide for programme managers. WHO/NHD/011, Second 2001.

37. Rah JH, Shamim AA, Arju UT, Labrique AB, Rashid M, Christian P: Age of onset, nutritional determinants, and seasonal variations in menarche in rural Bangladesh. J Health Popul Nutr 2009, 27(6):802-807.
38. Garnier D, Simondon KB, Benefice E: Longitudinal estimates of puberty timing in Senegalese adolescent girls. Am J Hum Biol 2005, 17(6):718-730.

39. Simondon KB, Simondon F, Simon I, Diallo A, Benefice E, Traissac P, Maire B: Preschool stunting, age at menarche and adolescent height: $a$ longitudinal study in rural Senegal. Eur J Clin Nutr 1998, 52(6):412-418.

40. Zeba AN, Prevel YM, Some IT, Delisle HF: The positive impact of red palm oil in school meals on vitamin A status: study in Burkina Faso. Nutr J 2006, 5:17

41. Kassaye $T$, Receveur $\mathrm{O}$, Johns $\mathrm{T}$, Becklake MR: Prevalence of vitamin A deficiency in children aged 6-9 years in Wukro, northern Ethiopia. Bull World Health Organ 2001, 79(5):415-422.

42. de Pee S, Brinkman HJ, Webb P, Godfrey S, Darnton-Hill I, Alderman H, Semba RD, Piwoz E, Bloem MW: How to ensure nutrition security in the global economic crisis to protect and enhance development of young children and our common future. J Nutr 2010, 140(1):138S-142S

43. Bloem MW, Semba RD, Kraemer K: Castel Gandolfo workshop: an introduction to the impact of climate change, the economic crisis, and the increase in the food prices on malnutrition. J Nutr 2010, 140(1):132S-135S.

44. PCD: The anthropometric status of schoolchildren in five countries in the partnership for child development. Proc Nutr Soc 1998, 57(1):149-158.

45. Beasley M, Brooker S, Ndinaromtan M, Madjiouroum EM, Baboguel M, Djenguinabe E, Bundy DA: First nationwide survey of the health of schoolchildren in Chad. Trop Med Int Health 2002, 7(7):625-630

46. Begin F, Habicht JP, Frongillo EA, Delisle H: The deterioration in children's nutritional status in rural Chad: the effect of mothers' influence on feeding. Am J Public Health 1997, 87(8):1356-1359.

47. Ye D, Drabo YJ, Ouedraogo D, Sawadogo A: [Weight profile of school age children in Ouagadougou (Burkina Faso)]. Arch Pediatr 2003, 10(7):652-653

48. Groeneveld IF, Solomons NW, Doak CM: Nutritional status of urban schoolchildren of high and low socioeconomic status in Quetzaltenango, Guatemala. Rev Panam Salud Publica 2007, 22(3):169-177.

49. Delpeuch F, Traissac P, Martin-Prevel Y, Massamba JP, Maire B: Economic crisis and malnutrition: socioeconomic determinants of anthropometric status of preschool children and their mothers in an African urban area. Public Health Nutr 2000, 3(1):39-47.

50. WHO/UNICEF: Focusing on anaemia: towards an integrated approach for effective anaemia control. 2004 [http://motherchildnutrition.org/nutritionprotection-promotion/pdf/mcn-focusing-on-anaemia.pdf].

51. Bhargava A, Jukes M, Lambo J, Kihamia CM, Lorri W, Nokes C, Drake L, Bundy D: Anthelmintic treatment improves the hemoglobin and serum ferritin concentrations of Tanzanian schoolchildren. Food Nutr Bull 2003, 24(4):332-342

52. Wang SJ, Lengeler C, Smith TA, Vounatsou P, Diadie DA, Pritroipa $X$ Convelbo N, Kientga M, Tanner M: Rapid urban malaria appraisal (RUMA) I: epidemiology of urban malaria in Ouagadougou. Malar J 2005, 4:43.

53. Semba RD, Bloem MW: The anemia of vitamin A deficiency: epidemiology and pathogenesis. Eur J Clin Nutr 2002, 56(4):271-281.

54. Mehdad A, Siqueira EM, Arruda SF: Effect of vitamin a deficiency on iron bioavailability. Ann Nutr Metab 2010, 57(1):35-39.

55. Mwanri L, Worsley A, Ryan P, Masika J: Supplemental vitamin A improves anemia and growth in anemic school children in Tanzania. J Nutr 2000, 130(11):2691-2696.

56. Maramag CC, Ribaya-Mercado JD, Rayco-Solon P, Solon JA, Tengco LW, Blumberg JB, Solon FS: Influence of carotene-rich vegetable meals on the prevalence of anaemia and iron deficiency in Filipino schoolchildren. Eur J Clin Nutr 2010, 64(5):468-474.

57. WHO: Salt as a vehicle for fortification. Report of a WHO expert consultation, Luxembourg 21-22 march 2007.

58. Fanjiang G, Kleinman RE: Nutrition and performance in children. Curr Opin Clin Nutr Metab Care 2007, 10(3):342-347.

59. Ahmed F, Khan MR, Banu CP, Qazi MR, Akhtaruzzaman M: The coexistence of other micronutrient deficiencies in anaemic adolescent schoolgirls in rural Bangladesh. Eur J Clin Nutr 2008, 62(3):365-372.

doi:10.1186/1475-2891-10-34

Cite this article as: Daboné et al: Poor nutritional status of schoolchildren in urban and peri-urban areas of Ouagadougou (Burkina Faso). Nutrition Journal 2011 10:34. 